\title{
Lessons in Casual Sex: Narratives of Young Swedish Women
}

\author{
Michael Tholander ${ }^{1} \cdot$ Ninni Tour $^{1}$
}

Published online: 31 December 2019

(c) The Author(s) 2019

\begin{abstract}
This study focuses on the narratives of four young Swedish women who were interviewed about their experiences of heterosexual casual sex. The analyses are based on a phenomenological approach and provide insight into a highly complex sexual practice, which the participants often portray as having lacked transparent communication, balance of power, and satisfying sex - three key dimensions of an everyday "sexual democracy." However, the participants also claim to have dealt with these problematic issues, hence pointing to the socializing role that early sexual experiences have for young women. Thus, if the participants' own perspectives of events are accepted, sexual empowerment might best be understood as individually colored, experience-based, developmental processes rather than as something that is brought about primarily through collective, formal sex education.
\end{abstract}

Keywords Casual sex $\cdot$ Phenomenology $\cdot$ Sexual democracy $\cdot$ Sexual empowerment $\cdot$ Sexual socialization

\section{Introduction}

Although Reay (2014) bemoans the lack of a historical perspective on the phenomenon of casual sex, and reminds us that the practice of uncommitted sex is not an invention of modernity, theoretical (Bauman 2003; Giddens 1992; Sigusch 1998) as well as empirical (Kalish and Kimmel 2011; Paul and Hayes 2002; Timmerman and Courtois 2018) scholars tend to describe it as a fairly new and growing practice. The plethora of empirical studies in this area over the last decade also suggests that an increasing number of researchers find casual sex to be an important topic of investigation (cf. Boislard et al. 2016; Farvid and Braun 2017; Rodrigue and Fernet 2016, for reviews of the field). In this study, we want to contribute to the field by analyzing the narratives of four young Swedish women who were interviewed on the basis of their experiences of heterosexual casual sex. A large-scale survey in Sweden (Public

Michael Tholander

michael.tholander@liu.se

1 Linköping University, Linköping, Sweden 
Health Agency of Sweden 2019) recently showed that at least 38\% of young women (16-29-year-olds) report having engaged in casual sex during the last 12 months. It is thus a very common practice in this specific cohort, dropping to $15 \%$ in the one that follows (30-44-year-olds).

As pointed out by Farvid and Braun (2018, p. 1405), the existing research literature on casual sex often constructs it as a "risky" practice. It is associated with unwanted pregnancies, sexually transmitted infections, mental problems, and other difficulties, and young females are identified as a particularly vulnerable group in numerous studies (e.g., Campbell 2008; Cooper and Gordon 2015; Dubé et al. 2017; Grello et al. 2006; Kennair et al. 2018; Owen et al. 2010). Although we do not deny the reality of these results, to which there are certainly exceptions (e.g., Eisenberg et al. 2009; Kaestle and Evans 2018; Vrangalova and Ong 2014), the aim of this study is not so much to identify the "factual" risks of casual sex, as to investigate casual sex as an experienced and retold social practice.

In analyzing the narratives, we use a phenomenological approach (Smith et al. 2009), through which we attempt to concentrate on the participants' views of their experiences rather than uncovering the real events. In doing so, we hope to provide an insight into a highly complex sexual practice, which the participants often portray as having lacked transparent communication, balance of power, and satisfying sexthree key dimensions of an everyday "sexual democracy" (Giddens 1992, p. 182). Yet, we also want to demonstrate how the participants claim to have dealt with these problematic issues. In this way, we hope to shed light on the socializing and empowering role that early sexual experiences have for young women. Thus, sex education, problematized by many scholars for being highly aligned with risk-oriented research (cf. Fine 1988; Kiely 2005; Lamb 2010), might not always be the most important source of influence on female sexual development.

\section{The Swedish Sin, Sexual Democracy, and the Pure Relationship}

Sweden has had a reputation of being a sinful nation long before the casual sex of today. According to Hale (2003) the concept of the "Swedish sin" gained currency in the early 1950s when the motion picture "One summer of happiness" shocked the world by showing the naked breasts of Ulla Jacobsson. It was soon followed by Ingmar Bergman's film "The summer with Monika," which was even more shocking, particularly in its portrayal of carefree, premarital sex. After this, an infamous article, "Sin \& Sweden," was published in "Time." It was written by an American journalist, Joe David Brown, and portrays Sweden as a deeply depraved country. For instance, Brown (1955) repudiates Elise Ottesen-Jensen, the founder of the Swedish Association for Sexuality Education, for openly recommending teenagers to have sex insofar as they are truly in love with each other.

Although Ottesen-Jensen's guiding principle may seem conservative today, Sweden has had a reputation as a nation of "unrestrained sexual freedom" (Hale 2003, p. 351) ever since Brown's disparaging spell. Yet, various parties have tried to offer an alternative picture of the Swedish sexual policy during the years and decades that followed (e.g., Ahlmark-Michanek 1962; Frantzén and Torekull 1970; Swedish 
National Board of Education 1977). The essence of this counterargument is that Swedish institutions and individuals promote a sound "sexual democracy" among its citizens. According to Glover and Marklund (2009), this sexual democracy implies that sexuality must be "rescued from both the irrationality of the barbaric state of nature, as well as from the irrational, religious and oppressive (moralizing) imperatives of traditional culture" (p. 504). It is thus associated with modernism, responsibility, and enlightenment rather than with the sort of primitivism, frivolity, and unbridled lust that Brown feared.

At the heart of sexual democracy lies not only the choice of "freedom and sex" over "promiscuity and sin," but, above all, an imagined transformation of the relationship between the sexes. Birgitta Linnér, a family counselor and sex educator of the $1960 \mathrm{~s}$, describes this as a "shift on a nationwide scale from the double standard of sexual morality to sexual democracy" (Linnér 1967, p. xv). The basic idea is that men and women should have the same rights and obligations when it comes to sexuality as in other areas of social life. Thus, as Linnér points out, the advancements in bringing about a greater equality between the sexes in politics, education, and employment would simply be followed in the more personal sphere of sex.

This type of trickle-down logic is also advanced by Giddens (1992) in his work on the transformation of intimacy in modern society. Thus, like Linnér, he draws a parallel between changes in the public and the personal sphere when he imagines "a wholesale democratising of the interpersonal domain, in a manner fully compatible with democracy in the public sphere" (Giddens 1992, p. 3). In a more general sense, Giddens's ideas also correspond very well with the Swedish version of sexual democracy, which continues to be supported today (cf. Public Health Agency of Sweden 2019). For instance, he launches the liberal notion of a "plastic sexuality," a sexuality freed from both "the needs of reproduction" and "the rule of the phallus" (Giddens 1992, p. 2), hence endorsing greater sexual equality, experimentation, and varieties of relationships. More importantly, he also invents a name for the ideal relationship: "the pure relationship."

According to Giddens (1992), a "pure relationship" exists when "a social relation is entered for its own sake ... [and] is continued only in so far as it is thought by both parties to deliver enough satisfaction for each individual to stay within it" (p. 58). But does this definition pertain to casual-sex relationships, the topic of our study? Following Giddens, we argue that it does. A pure relationship does not imply that the relationship must be long-lasting or emotionally intimate, as long as the parties agree on this. The main issue is not the length or the depth of the relationship, but that those involved stand behind a consensual agreement. Thus, as against expectations, casual sex "is not inherently incompatible with emergent norms of the pure relationship" (p. 147). In practice, though, and as we will show below, a pure relationship might be very challenging to establish in real-life casual sexual relationships.

On the basis of the above discussion, this study focuses on three dimensions of the pure relationship that would seem important for sexual democracy among casual sex partners: (1) Transparent communication, that is, "open discussion by partners about the nature of the relationship" (Giddens 1992, p. 192); (2) Balance of power, that is, "a relationship of sexual and emotional equality" (p. 2); (3) Satisfying sex, 
that is, "the achievement of reciprocal sexual pleasure" (p. 62). These aspects of a pure relationship translated to our study as the following research questions during the analysis: How do the interviewed women (1) describe the communication with their casual sex partners, (2) portray power issues in relation to their casual sex partners, and (3) assess the sexual activities they had with their casual sex partners? Note that the participants were not asked these questions explicitly, but spontaneously oriented towards them during the interviews.

It should be emphasized that in performing the analysis, we have tried to abstain from automatically constructing casual sex as a risky practice. As an overwhelming number of studies have already shown that women fare less well than men in this particular practice (see above), a reasonable presumption of this study would be that sexual democracy, as somewhat naively envisioned by Giddens (1992), has already been proven elusive. However, in keeping with a phenomenological approach, we wish to present a more nuanced picture of women's narratives of casual sex than this. Our analyses not only show that women express dissatisfaction with their experiences, but also that those experiences have transformed them into who they are now. This socializing aspect of casual sex, imagined or real, has rarely been highlighted in research (but see Bryant and Schofield 2007; Morgan and Zurbriggen 2007; Peterson 2010). Our argument is that a greater sexual democracy not only rests on previous advancements in politics, education, and employment, as suggested by Linnér (1967), or on advances in sex education, but also on learning from personal experience.

\section{Method}

\section{Participants, Interview Procedure, and Ethics}

As the purpose of the study was to focus on young women's experiences of heterosexual casual sex, the following three inclusion criteria were stipulated: female sex, 18-25 years of age, and at least one experience of heterosexual casual sex. All four participants were recruited through an information sheet on a social media platform, and none of them were compensated for participating in the study. Their pseudonyms and ages are as follows: Anna (25), Bella (25), Clara (22), and Disa (22).

All participants identified as cisgender, white, middle-class, and city dweller. Anna, Clara, and Disa identified as heterosexual, and Bella as bisexual. Anna, Bella, and Clara were living together with a partner, and Disa was single. Anna, Bella, and Disa were all studying at university, and Clara worked as a nurse. Smith et al. (2009) argue that this type of homogeneous and small sample is concordant with the ideographic interest of interpretative phenomenological analysis (see more below). The sample represents population perspectives rather than population averages.

All interviews were performed by the second author and lasted between 45 and $75 \mathrm{~min}$. During interviews the participants were asked to elaborate freely on their experiences and thoughts, but were also asked questions such as: Why did you engage in casual sex? What are your experiences of casual sex? How did you feel 
in the moment? How did you feel afterwards? Did you experience any differences between different occasions of casual sex?

The study was conducted in concordance with ethical research principles in Sweden, including informed consent, confidentiality, and usage rules (Swedish Research Council 2011). Despite focusing on a potentially sensitive topic, none of the participants expressed discomfort when asked about this in a direct question after the interviews were concluded.

\section{Interpretative Phenomenological Analysis}

Interpretative phenomenological analysis (IPA) is an approach that examines how individuals interpret and ascribe meaning to their lived experiences (Smith et al. 2009). The interest in the "lived experience" of people comes from phenomenology and implies that we can only understand various phenomena if we ask those with direct experience of it. The emphasis on "interpretation" is a contribution from hermeneutics and involves a focus on how people come to make sense of their particular experiences. Indeed, there is a double hermeneutics at play, as the analyst attempts to interpret people's own interpretation of their lived experiences.

As pointed out above, IPA is thoroughly ideographic, focusing on the particular rather than the universal. In line with this, it has not been our ambition to produce results that can be generalized to large number of people, but rather to understand casual sex from the perspectives of those involved in the study. However, interpretations based on a detailed examination of a small number of narratives might still lead to theoretical insights that transcend the studied material. For instance, smallsample studies often provide opportunities for "naturalistic generalization," a kind of generalization that is left to the reader to perform on the basis of his or her prior experiences and knowledge_or lack thereof (Stake 1978). In the same vein, such studies are also an important means of acquiring "vicarious experience" through the (indirect) study of others.

After transcribing all of the interviews, we followed the analytical steps presented by Smith et al. (2009). A brief description of this process includes close reading of the transcripts, open coding, identification of possible themes, comparisons between different interviews, and selecting illustrating quotations. In reality, the process is very complex and involves a series of restarts, alterations, and reorganizations.

More importantly, and perhaps somewhat untypically for an IPA study, we allowed the concept of "sexual democracy" to be introduced quite late in the analytical process. This concept fitted some of our themes and it made us approach our data in a more targeted way than otherwise had been the case. With this concept in mind, all themes in the data did not stand out as equally relevant anymore. Moreover, the concept helped us to choose exemplifying quotations and organize the presentation of the results.

After singling out quotations that could illustrate our themes, we proceeded with a deeper examination and engaged in expanding rather than condensing the analysis. In short, we tried to create "added value" in relation to all of the quotations (Smith et al. 2009, p. 23), that is, to point to details in them that perhaps were not instantly 
apparent. To create this added value, we went beyond mere description of individual quotations to ask questions such as: What is being said between the lines? What is the underlying message? What hidden assumptions, ideals, and normativities can be spotted? Moreover, added value was also created by connecting findings in an individual quotation to the larger data set as well as to relevant previous research and theory.

\section{Results}

Just like Farvid and Braun's (2017) interviewees, our participants describe, interpret, and evaluate casual sex practices that are highly varied, contradictory, and multifaceted. In this result section, we present some of what they articulated under three analytical headings: lessons in sexual communication, lessons in power dynamics, and lessons in ars erotica.

\section{Lessons in Sexual Communication}

Previous research indicates that those who engage in casual sex rarely communicate the exact status of their relationship (Fahs and Munger 2015; Moran and Lee 2014; Weaver et al. 2011). Is casual sex the beginning of a serious relationship or the proof that no such relationship will ever develop? Peplau, Rubin, and Hill (1977) argue that there are two opposing answers to this question. One view insists that sex is an effective means of building emotional intimacy, whereas the opposing position claims that sex may short-circuit intimacy and prevent the development of closeness and commitment. As Giddens (1992) points out, the latter view has dominated.

In this section, we analyze how the participants reason about sexual communication in relation to their experiences of casual sex. In particular two of the participants portray themselves as having gradually become better at interpreting the nature of sexual encounters. In our first example, Anna describes her naivety of youth:

I try to remember my sixteen-year-old self and how I felt [after having had sex]. I believe "disappointed" would be the right word. I mean, I had thought that it would mean something. You know, we did talk for quite a while too. I mean, it really felt like "well okay, was this it?" (.) Yeah, I guess I was disappointed (.) I guess I can't explain it in any other word than "disappointed" [...] You know, when you think about sex, relations, love - you kind of thought that it would lead to something else. (Anna)

In this quote, Anna uses the word "disappointed" three times in order to express how she felt after an early sexual encounter. Her hope that it would "mean something" and "lead to something else," presumably a committed relationship of some sort, obviously fell short soon after the encounter. Notice also how she justifies that she had a good reason to expect something more: "we did talk for quite a while too." This formulation shows that Anna experienced that she had reached below the emotional surface with her partner, and that they therefore had engaged 
in something more that plain sex. Talking for "quite a while," as well as having sex, are "markers of intimacy" (Giddens 1992, p. 139), and these aspects of the encounter misled Anna into believing that they had started to build a relationship that would encompass both sex and love. The words in past tense at the very end, "you kind of thought," signal development and suggest that she would not make the same mistake today.

Bella describes an even more confusing event. She has had a secret crush on a young man when she suddenly bumps into him at a camping ground and have sex late at night. Immediately afterwards, she is very concerned:

"Will this lead to something with this guy?" (.) "Between us?" (.) "What happens next?" you know. Um, but there was just a short, short moment between us getting dressed again until he mentioned that he was about to start dating someone. That certainly got me thinking. But there was not, there was not much time to keep thinking, 'cause then I realized that "okay, this was a one-off event, it won't happen again" (.) um (.) but still you, you kind of wondered "how does he feel now?" (.) "does he want more or not?"

(.) um, like tomorrow, or like further ahead. (Bella)

In their study of online advice on casual sex etiquette, Farvid and Braun (2013) argue that clear communication is key in any casual sex encounter. Related to the notion of "sexual democracy," both parties should be "completely" honest "before" engaging in sex (p. 366). Here, Bella reports the confusion it causes when her partner is completely honest, but only after the sexual act. Barely has she started wondering where the relationship might be heading, before he reveals his dating plans. Only then Bella realizes that she has experienced her first onenight stand, although she, as the very end of the quote shows, still retained some hope even after this bitter realization.

The reasoning of both Anna and Bella suggests that they had already developed an idea of a committed relationship when they engaged in sex, but that they then discovered a "romance gap" (Lovejoy 2015, p. 477) in relation to their partners, that is, having unrequited romantic feelings towards them. Thus, in the heat of the lived moment, they did not engage in casual sex at all, but were anticipating a continued relationship. However, when they become more experienced, a more cynical approach to sex and sexual communication appears. For Bella this means that she appropriates the rule of her partner above: as long as there has been no explicit communication of a committed relationship, no party should expect this after sexual activities. When Bella ends up having sex with a male friend, she makes use of the rule:

We didn't plan to have sex [...] but later both he and my ex thought we were a couple. And in my head, we were not, 'cause there had been no discussions about that. No one had asked the other about going steady, and it was(.) No, in my head this was a one-off event (.) Um, "now he leaves my place and we're still friends" (.) But, um, we haven't talked since then (.) so (.) I guess we're not friends anymore. (Bella) 
When Bella in this quote makes complaints about her male friend, who jumps to conclusions after their spontaneous sex, she twice refers to "in my head," supposedly to distance herself from his understanding. With her earlier encounter she experienced a sort of romance gap in relation to her partner, that is, having unrequited romantic feelings for him, but here the reverse situation is presented. Note also how the lack of explicit communication before having sex turns into no communication after it. As pointed out in previous research (Lovejoy 2015; Wentland and Riessing 2011; Weaver et al. 2011), adding sex to a friendship often changes something with the relationship, including losing contact, as in this case.

In contrast to Bella, Anna instead begins to orient towards the rule of explicit communication before the sexual act, which sexual advisors often recommend (cf. Farvid and Braun 2013):

[I had no wish for a relationship] on my part. I told, I told this person that "no, this is it, no more!", 'cause I didn't want, I didn't want anything more with this particular person. We had sex, it was fun, that's enough! (Anna)

Anna here resembles the type of "sassy woman" that sex advisors often promote as desirable, a woman who is sexually liberated, assertive, and independent, and "capable of doing and getting whatever she wants" (Farvid and Braun 2014, p. 126). This sassiness fits well with the use of explicit communication, "this is it, no more!", as well as with a "sexual instrumentalism" (Lovejoy 2015, p. 476) in which lovemaking transpires without any emotional ties, "We had sex, it was fun, that's enough!"

Clara differs from both Anna and Bella, but also from Disa (who is presented in later sections): Clara never during the interview portrays herself as having been shackled with the naivety of youth, and she argues that explicit communication is superfluous:

To me, it is pretty obvious that if you try to hook someone up that you haven't talked to during the entire night, like ten minutes before you're about to leave [the pub], and then both parties kind of show interest, then (.) it (.) well, it becomes quite obvious that you'll walk home together [...] Then you probably only expect to get laid and then you leave the day after [...] I don't think I've ever expected more. If I had, I would probably not have walked home with that person. (Clara)

Clara here defends the idea that people can judge from the context whether or not to expect casual sex (cf. Beres 2010); the pub environment, closing time, absence of previous romantic contact, hookup lines, and a sparking interest are all implicit markers of an interest in casual sex. Hence, there is no need to engage in explicit dialogue, which might ruin the mood and the feeling of spontaneity (cf. Kalish and Kimmel 2011). Note also how Clara, in contrast to Anna and Bella, claims to have understood this implicit sexual communication from the very start: "I don't think I've ever expected more." Moreover, at the very end of the quote, she supports the view that casual sex actually limits your chances to pursue a committed relationship (cf. Peplau et al. 1977, above). Well in line with a sassy stance, she is not making herself any naïve illusions that casual sex will ever lead to anything but sex. 
Yet, in subtle ways, Clara later inadvertently discloses that she is still, sometimes, open to consider more. When she relates the events of her last one-night stand, a small word at the very end is telling:

He was like really- (.) gave compliments and (.) he (.) well, we were kind of spooning and he was very cuddly afterwards, even though we just kind of had sex with each other. And both of us knew that I would leave the next morning, probably. (Clara)

This little word, "probably," leaves room for an alternative trajectory. Even if Clara is sassy, and far from naïve, there still seems to be space for imaginings of a committed relationship. But a potential "morning renegotiation" of the status of the relationship would not necessarily mean than she abandoned the vague idea of a pure relationship that seems to be articulated in the quote. It could be a different pure relationship, perhaps one involving love and romance.

This orientation towards something more than merely sex is also visible in Clara's acquired skill in critical appraisal of Tinder exchanges:

I can read the signs rather clearly [at Tinder]. You know, if I write that I study behavioral sciences and they just reply "okay," then I just "whaaat?!" Or if they-, or if I explain that "but I have to study during the days," and they just "well, okay." You know, when they don't even ask questions about my studies, then it becomes quite obvious that they are not very interested in me as a person. (Clara)

This quote shows that when Clara judges potential partners in the virtual world, she makes inferences on the basis of their chat input. If their comments suggest a lack of interest in her as a person, she is morally provoked ("whaaat?!") by the instrumental orientation towards sex. Thus, even if she is mainly looking for sex, there should obviously still be room for some sort of relationship to develop. If not, her interest cools off. Recent research also confirms that many Tinder users, as opposed to the persistent reputation of Tinder as a "hookup application," indeed use the platform to give themselves the chance to establish a committed relationship (Timmermans and Courtois 2018).

\section{Lessons in Power Dynamics}

As Hird and Jackson (2001) point out, heterosexual discourses paint a picture of "active, persistent and powerful" men getting their way with "passive, receptive and responsive" women (p. 28). The narratives in this study partly confirm this picture, but also add a temporal dimension that fits less well with this one-sided view. Through the passage of time, and by way of further sexual experience, the women begin to look at their previous sexual life in a new light and starts to act as empowered women, expecting sexual equality, or more. If we do not recognize this temporal or experiential dimension, we run the risk of "constructing female sexuality solely in terms of victimization" (Hird and Jackson 2001, p. 41) rather than as something dynamic and developing. 
In the first quote, Disa explicitly portrays herself very much in line with the power dynamics of prevailing heterosexual discourses, that is, as acting in accordance with the "male domination, female compliance" script (Kalish and Kimmel 2011 , p. 42). However, already from the start, she also clearly marks herself as changed:

I didn't really understand that it should be on equal terms (.) um, and I guess I allowed myself to be- (.) even if I did not feel for it, it was impossible to say "no," "cause they expected certain things. And you felt that "well, now I've been hanging with him, now I've got to do this." You couldn't say like "no, let's skip this, I don't wanna do it." You just offered your body. And I think it happens all the time for women, unfortunately. It feels like you've got some kind of obligation to give men something they expect of you. If they have offered a drink, or whatever [...], you shouldn't give them this odd expression "blue balls." [...] It's awful when you think about it, really, 'cause it resembles rape, 'cause (.) um, even if I don't say “no," I don't want to do it. (Disa)

Already the first few words imply that Disa speaks from the experienced woman's horizon: she now knows that it should be "on equal terms," but in the early days, she "offered" her body. Three aspects in her narrative are particularly noteworthy. First, early in her sexual past, Disa claims to have been pulled into situations in which sex was traded for other favors, including getting drinks, a car ride, or a bed for the night (the two last things mentioned elsewhere in the interview). Thus, in a game of "expenditure and profit" (Foucault 1986, p. 30), she felt obligated to yield a return on preceding male investments. Second, Disa felt a strong sense of being committed to deliver sex lest the insatiable males, a bit pitiably, would succumb to "blue balls" (a colloquial term to describe supposed pain associated with arousal in men without orgasm). Thus, in line with the "male sexual drive discourse" (Hollway 1989, p. 54), which contends that men's sexual desire is biologically driven, uncontrollable, and in need of release through orgasm, she had to perform a sort of sexual rescue operations. Third, although Disa probably did not view these sexual encounters as "rape" in the lived moment, the temporal displacement tempts her to construct it as such during the interview. All these aspects indicate power imbalances, and they confirm Hird and Jackson's (2001) thesis that sexual coercion operates through a normative heterosexuality in which women respond to, rather than initiate, sexual activity, and where acts of milder or stronger dominance are often cast as normal behavior (cf. also Farvid and Braun 2018; Moran and Lee 2014; Paul and Hayes 2002).

A second major source of power imbalance was encountered already in the last section: the romance gap. Below, Bella describes the painful rumination that this power imbalance once caused within her, but also how she now comforts herself:

I had feelings, but he had no feelings (.) so, well (.) it happened only once [...] So I kind of thought a bit like "well, am I not good enough?" and "well, why did you do this to me if you're not interested?" (.) and that kind of questions that will never get any answers (.) But sure, I imagine that everyone that has one-night stands, um, that in some cases one of the parties has feelings and in some cases no one has feelings, but it's only a physical thing. And lots of 
thoughts are spinning in certain heads and "yes, mission accomplished!" in the heads of others. (Bella)

After having realized that the sexual encounter "happened only once," Bella was haunted by self-doubting questions. The second question, "why did you do this to me if you're not interested," is asked in present tense and takes her back to the moment of deceit. By presenting herself as a vulnerable object that has been damaged, she makes the power imbalance highly salient and subscribes to a type of "phallocentric" understanding of heterosexual sex as something that "men do to women" (Jamieson 1999, p. 484). But then Bella comforts herself with the voice of a more experienced woman and suggests that this type of imbalance probably is common in one-night-stand situations. She now realizes that it is something to be wary of and that she is not the only victim of all those people who, because of their romance-gap advantage, can afford to exclaim "yes, mission accomplished!" and move on to the next target.

In the interviews, the participants claim to have dealt with power imbalances of the above type in at least three different ways. One way is to revert the power imbalance, as Anna describes:

Perhaps someone used me the first time, whereas I perhaps used this guy the last time (.) I mean, the table has kind of turned hahaha [...] You were so insecure, when you were young. Everyone had to like you. But the last time I had a one-night stand, which turned into several, I was the one who took the initiative. You can notice a (.) a transformation (.) in my own way of thinking (.) in the way I'm carrying myself and how I (.) kind of talk with guys [...] I have grown in myself. But perhaps I dislike who I became, you know. From being (.) sort of exploited emotionally the first time to being the perpetrator the last time [...] But I mean, I still think I've become a stronger person [...] I mean from being this little girl to being the one with all the power. (Anna)

This quote illustrates the remarkable transformation that Anna claims to have passed through during the last decade. Once being a "young," "used," and "insecure" teenage girl, she has now converted that into the maturity, initiative, and strength of a young woman. However, the metaphor used, "the table has turned," not only includes the noble effects of this transformation, but also the spiteful. Anna now describes herself as an autocratic perpetrator rather than the powerless victim, and no real sexual democracy has resulted from her transformation. The advantage of a romance gap gives her the edge, and she exploits it for her own good. Already when Waller (1937) analyzed early dating practices, he made a comment on this very phenomenon: according to "the principle of least interest" (p. 733), the one who is less interested in the continuation of an affair is the one in control. But recent studies on casual-sex practices present the same picture. For instance, an interviewee in Moran and Lee's (2014) study describes a similar position as "empowering" (p. 218), making it easier for her to enjoy sex for its own sake. However, above we can note that Anna obviously struggles with the image of herself. She openly declares that she dislikes who she has become, while also being happy with her powerful position. In quite a self-exculpatory 
manner, she elsewhere in the interview tries to ease this struggle by stating that her partner at least "had the chance to say no." When she was exploited, she was not given this opportunity. Certainly, the romance gap is a power gap, but she did not employ it in the worst imaginable way.

Another way to deal with a power imbalance is illustrated by Clara. Below, she recounts a planned rendezvous, the second time around with the same partner, which she ends up simply cancelling:

I was about to meet him, but I, at that point it felt, I wouldn't say too cheap, but I would say it was too much on his terms, um (.) and um (.) But it is a difficult balancing act between what $I$ think, and what $m y$ terms and $m y$ thoughts about it are, and society's, in terms of cheapness. I definitely didn't view it as-, you know, for me it was a sort of fun and cool thing. Until I started to think about it [...] You know, I was gonna walk to his place, he wouldn't meet me, I didn't know the way, we would only have one hour. It all appeared too much like "well, these are your terms." I was just gonna show up, and then I, then I would sort of leave. (Clara)

In accounting for the planned event, Clara vacillates between her own view of the encounter as "a sort of fun and cool thing" and a gut feeling that society, and perhaps also a part of herself, would deem it as "cheap." Both parties had previously had casual sex in complete agreement that it was only sex, and in this sense, it resembled a pure relationship. But the second time around, Clara cancels the meeting anyway. When the sexual encounter appears too instrumental (no meeting point, no directions, limited time frame), and too one-sidedly stipulated by her partner, she finds herself near the bottom of the sexual "hierarchy of respectability" (Farvid and Braun 2013, p. 369). Hence, in an instance, the power imbalance obviates the possibility of both a pure relationship and a second rendezvous.

A third way to deal with power imbalances is simply to act proactively and make sure that they never arise. Disa explains:

[It is important] that no emotions are involved, and that it occurs on equal terms, that both parties know that no emotions will be allowed to develop. It's all about being de facto able to have sex only. (Disa)

Disa here describes how casual sex ideally should work. Very much in line with sexual advisors' rules of sexual etiquette (Farvid and Braun 2013), there should be an explicit deal that no emotions will be involved and that both parties know this beforehand. This ideal, however, only seems to be a theoretical construct. In reality, neither Disa nor the other participants describe that this is how it has worked for them. Instead, there has often been miscommunication, exploitation, romance gaps, and so on, but also, at times, satisfying sex. For these or other reasons, "being de facto able to have sex only" is perhaps not possible for everyone, as both sex advisors state (Farvid and Braun 2013) and as Disa points out. Or if it once was possible for a particular person, it might not have stayed that way. Later in the interview, Disa ultimately declares that she is "done with that shit" (in reference to casual sex), because it is so "awkward." Similarly, Bella clarifies that 
she "won't ever do it again," simply because she now wants "the emotions, from both parties." Thus, in their current lives, engagement in casual sex is construed as a bypassed stage in their sexual development.

\section{Lessons in Ars Erotica}

Foucault (1978) makes a well-known distinction between scientia sexualis (sex science) and ars erotica (erotic art). The disciplinary ambition of the former is repudiated for its non-erotic truth claims, and perhaps also for teaching us that sex is "the source and scene of oppression, inequality, violence, abuse, and deadly infection" (Sigusch 1998, p. 335). The latter, however, is praised for its ambition to assess sex in terms of "its intensity, its specific quality, its duration, its reverberations in the body and the soul," which is then supposed to be "deflected back into the sexual practice itself" (Foucault 1978, p. 57). In this section, we focus on what the participants have to say about the quality of their sexual experiences, that is, their own lessons, or non-lessons, in ars erotica.

One would imagine that if sex is the objective of the encounter, both parties of a casual sexual encounter ought to make the best of it. The narratives of our participants are of course more complex than this. Clara explains that "the span of what you get in one-off events can be rather wide" and presents an example from the very bad end:

There are a few douchebags out there [...] My worst example, he dipped it, came, and left [...] He was kind of a creep, and I was stunned that someone (.) could behave like that [...] He said "well, get undressed then!" sort of (.) It was really a very unexciting situation for me. He basically sort of expected that I would get super horny just by looking at him, which I did not, 'cause he kind of thought that he could just put it in (.) And I just "well, it doesn't work like that!" um (.) um, and then he basically wanted me to fiddle with myself until he could put it in. And I certainly didn't go along with that! (Clara)

What this quote illustrates is a clear case of sexual instrumentality, distance, and objectification (cf. Fredrickson and Roberts 1997). Although Clara and the other participants seem to agree that casual sex should not be too romantic, like a "candlelight" experience (Farvid and Brown 2013, p. 366), it is not acceptable if it becomes too standoffish either with off-putting orders and distancing markers, as in the case above. Indeed, contrary to what could be expected, research has shown that casual sex encounters are experienced as more satisfying when they borrow elements from the romantic genre, for instance, kissing, cuddling, and small talk (Karlsen and Traeen 2013; Paul and Hayes 2002; Weaver et al. 2011). But the example above perhaps also prove Giddens's (1992) thesis that seduction, and the willingness to make an effort, for some men might have lost much of its meaning in a society in which women have become increasingly interested in casual sex. "Douchebags" and "creeps" are names that these men may then be deserving of, but later in the interview Clara also emphasizes that if something like this happened today, she would ask the guilty party to leave, once again pointing to the socializing effect of past 
experiences. In relation to the case in question, she also adds a one-liner: "I can imagine that no one wants to sleep twice with that guy!"

Similarly, Disa points to this socializing effect of early experiences when she assesses the (dis)pleasure of casual sex at different points in time:

I kind of felt that my body didn't belong to me, but my body existed for other people's pleasure. But, of course, later it was used for my pleasures too, [...] 'cause one thing doesn't have to exclude the other, I believe. But I didn't understand that. At that point in time. I had such a twisted picture of what a woman should be like, or what, what $I$ should be like. (Disa)

The "twisted picture" of womanhood in the early days meant that Disa sacrificed her own sexual gratification for a phallocentric understanding of sexual pleasure as men's business (cf. Jamieson 1999). Her body was their body. But obviously she was later able to form a more "autonomous female sexuality" (Hird and Jackson 2001, p. 41) that afforded pleasure to her as well. She recaptured her body and developed another relationship to it, one that allowed and included ars erotica.

Clara, however, does not reach satisfaction through casual sex even when she shuns "douchebags" and "creeps." Indeed, she seems to have given up the idea of having an orgasm altogether through casual sex:

You know, one-off events are mostly in-and-out sex [...] My experience is that you don't waste too much energy on like (.) um petting and stuff (.) like practice oral sex. Sure, it might have happened sometime, but it's not-, it doesn't feel like you're putting your efforts on that (.) And as I don't get an orgasm if you don't do that, then I almost never come during one-off events. (Clara)

Clara's description of orgasmless casual sex confirms results from previous research. For instance, Kalish and Kimmel's (2011) hookup survey shows that only one in five women reported reaching an orgasm during casual sex. However, it is important to realize that sexual satisfaction does not even need be on the agenda when women (and men) engage in casual sex. Disa emphasizes this when she, during the interview, clarifies that she has engaged in casual sex for a number of reasons: to comfort herself for broken relationships, to silence friends who demand sexual activity, to get attention, to seize an opportunity, or to fill up a sexual bucket list. Similar motives for casual sex have also been presented in previous research (Cooper and Gordon 2015; Hatfield et al. 2012; Lyons et al. 2014).

Despite presenting these alternative motives for casual sex, and despite claiming to be "done with" this practice, Disa expresses feeling very satisfied with some of her experiences. Of all the participants, she gives the most vivid account of an affirmative ars erotica:

[Through casual sex I've] felt that my body is attractive, that my manners and the whole of me are attractive. And this gives me confidence in some sort of way, and it makes me feel (.) um (.) feel that I'm kind of good. To realize that a partner appreciates certain parts of me that I perhaps had not expected that he would (.) um (.) appreciate. Perhaps a part of myself that I've struggled to appreciate myself. Then you hear "wow, I think that's a 
really sexy thing with you," sort of. Then you can, then you become a bit like, "aha, damn, that's perhaps a bit of a sexy part of me then" hahaha. And then I remember that part and feel a bit elevated [...] "Perhaps I should start to develop my relationship with exactly this body part, or with this sound, or with the way I perform certain things," you know. (Disa)

Disa here describes something very different from "in-and-out sex," even though she is also being objectified by her partner. She gets compliments as part of having casual sex and not only learns to look at herself in a more appreciating way, but also remembers it for future use, hence allowing specific exciting body parts, sounds, and manners to be "deflected back into the sexual practice itself" (Foucault 1978, p. 57). Her reasoning also supports Nussbaum's (1995) argument that "all types of objectification are not equally objectionable" (p. 256). When Disa take notice of the passion and desire that her own body elicits in her partner, she profits from this, despite being treated as an object for lust fulfillment. What is decisive is that she is not merely or primarily treated as an object, hence opening up for a lesson in ars erotica.

Anna is also very celebratory of her best experiences of casual sex. At one point, she enumerates the positive associations that casual sex invoke in her: it is "fun," "pleasurable," "happiness-inducing," "exciting," "mystic", and "hazardous." Then she finishes off by stating that "anything can happen" and by comparing casual sex to flying, a metaphor that signals adventure, escapade, and meeting with the unfamiliar. A moment later, she recounts how an unknown man gratified her sexually in novel ways:

Oops, now he has shaved my pussy! I mean, hahaha, what will happen now? So (.) well- (.) And I can tell you that we had suuuch good sex! And I don't understand how, but it was really good (.) He turned me around in all kinds of positions, and I couldn't keep up with him. At all! Hahaha, I just "wooow!" hahaha "wow!" (.) Then I fell asleep quite nicely, you know! (Anna)

Such vivid portrayals of gratifying sex should be contrasted with all the adverse consequences that is often associated with casual sex in the research literature: sexual regret, abortion, STIs, sexual coercion, psychological problems, and so on (e.g., Campbell 2008; Cooper and Gordon 2015; Dubé et al. 2017; Hird and Jackson 2001; Kennair et al. 2018). In many ways, these two alternative characterizations represent two sides of the same practice, ars erotica and scientia sexualis, and these are not mutually exclusive.

Finally, it needs to be pointed out that three of the participants, Bella, Clara, and Disa, currently defend the idea that ars erotica is something that primarily has the chance to develop in committed relationships. While expressing this idea, Disa also conveys the impression that she has formed a more relaxed attitude towards sex through the years:

Lots of commercials and media kind of focus on how you get him to come after five minutes or so. But that's not where my attention is today, that I 
should become some kind of sex guru. But maybe I-, I probably focused on that when I was younger, that I would sort of become this person with a rumor of being good at sex. Um, today I guess it's more like "well, I have my sex and it's good" sort of (.) Like that! (.) It's not my main focus in life, but just an additional ingredient [...] And my experience is that it takes a long time to build a relationship where sex actually gets good, relatively good. Um, 'cause there are a lot of things to take into account and learn what people like and stuff, so I prefer to have sex with people in a relationship over a longer period, where you get confidence in each other and, well, where emotions are involved. That's something I like today. (Disa)

An early ambition to qualify as a "sex guru" meant that Disa had to orient towards some form of ars erotica. However, it is also obvious that she did not do this for her own sexual gratification, but rather for her social reputation as someone worthy of sleeping with. Paradoxically, when she today views sex as less important, a more relaxed or tranquil ars erotica has developed within stable relationships. Here, learning over time, mutual confidence, and emotional closeness become important elements that generate "good," or at least "relatively good," sex.

Similarly, Clara defends sex within relationships, while deconstructing the picture of casual sex in entertainment media:

I've probably never had a one night stand as good as the sex I've had in a relationship [...] Having one-off things, well, it's nice and fills a function, but [...] it's not very common that it resembles the movies, that it's kind of impossible not to touch each other. You know, like the exaggerations always shown in the movies. (Clara)

Similar critical views of casual sex have also been expressed by participants in previous research (e.g., Campbell 2008; Farvid and Brown 2017; Lovejoy 2015). Although it might be a thrill in the moment, many research participants report that casual sex falls short in comparison with "the real thing," as Bella expresses it. Her personal ars erotica, like that of Clara and Disa, must now include emotions in order to work. In this sense, their views reflect the first handbook on sex education in Sweden (Swedish National Board of Education 1957), which states that "sex only reaches its full development when conjoined with love" (p. 10). However, while this reasoning might sound awfully conservative to some people, nothing in our data suggests that one's sexual profile and ideology are carved in stone. The sexual lives and perspectives of these young woman, as for all of us, may change in future.

\section{Discussion}

In the mid-1960s, the Swedish sex educator Birgitta Linnér declared that in many parts of the world, Sweden is known as "a country with free erotic practices" (1965, p. 3). Today, this reputation, possibly colored by wishful thinking or moral indignation, might still be active, although Sweden perhaps never really represented an anomalous case. At any rate, Sweden of today does not seem to report significantly 
higher levels of "casual sex," the focus of the present study, than other, comparable countries (cf. Fahs and Munger 2015; Farvid and Braun 2017; Public Health Agency of Sweden 2019). Moreover, the results of this study suggest that the practice itself is characterized by the same strains and struggles as elsewhere, despite the high ambitions of official Swedish sex policy to promote sexual democracy (cf. Public Health Agency of Sweden 2017, 2019; Swedish National Agency for Education 2014).

The current study focused on the narratives of four young Swedish women who were interviewed about their experiences of heterosexual casual sex. Using a phenomenological approach (Smith et al. 2009), we investigated whether the practice of casual sex ever resembles "the pure relationship" (Giddens 1992, p. 58), that is, an ideal democratic liaison in which open communication, power balance, and gratifying sex conjoin to form a perfect whole, albeit only temporarily so. Against the backdrop of previous research, which repeatedly has pointed to casual sex as a risky practice (e.g., Campbell 2008; Cooper and Gordon 2015; Dubé et al 2017), it is not surprising that our analyses disclose several imperfections in relation to this ideal. Yet, the narratives also convey the sense of an awakening among the participants, which points to a socializing influence of sexual encounters. Explicitly or implicitly, the participants argue that opaque communication, power abuse, and lousy sex belong to their history rather than to their future.

One way to understand the narratives of the participants is to view them as accounts of "transformative moments" (Bryant and Schofield 2007, p. 331), that is, as events that have changed the trajectory of their sexual attitudes, behaviors, and identities. Through such transformative moments, and perhaps also through more mundane events, the women in the study convey the impression that they have gained a sense of sexual selfhood over time. Although this by no means imply that all of the women have developed an equally "sassy" approach to sex, they all convey an image of having escaped the position of the "vulnerable" woman, who does not know how to look after herself sexually and relationally (cf. Farvid and Braun 2014).

Whether we attend to positively or negatively colored transformative moments, the types of socialization that can be identified in the narratives are of two sorts. First, there are transformative moments in which learning is portrayed as having taken place in immediate connection with the sexual experience. An example of this would be Bella's narrative of how her partner, right after their spontaneous sex, discloses that he is about to start dating someone else. She then instantly understands that she has had her first "one-night stand" after mistakenly construing the intimate talk that preceded the sexual act as an initial step towards a relationship. Afterwards, she laments her own naivety and develops a more cynical attitude towards sexual encounters and sexual communication. Second, there are also transformative moments in which learning appears to have taken place on reflection, sometimes perhaps even as late as in the research interview itself. An example of this type of reflective transformative moment is when Disa, during the interview, suddenly seems to realize that certain manipulative or coercive practices enacted by her partners could imply that she essentially was subjected to rape during her early sexual past. 
In line with Bauman (2003), both these examples illustrate "the ambiguity of the sexual encounter" (p. 51). There is always a before, a present, and an after, which affect how people look at, and readily adjust their view of, any encounter that has involved sexual activities. In particular, all of the participants retrospectively downgrade much of what they experienced early in their sexual past (cf. Feldman et al. 1999). It is thus problematic to sustain a realistic concept of casual sex, in which events have an inherent value, as it prevents us from exploring the ways in which sexual experiences, and transformative moments, are interpreted within different time frames and within different contexts.

Through transformative moments, the participants often, directly or indirectly, claim to have changed their sexual behaviors, relational preferences, and preparedness for sex. In essence, this means that issues connected to communication intricacies, power dynamics, and sexual quality - the tripartite focus of the study - are portrayed as being handled differently in their current lives than before. Naturally, this presentation of themselves as more sexually knowledgeable could be an artefact of the interview situation and hence the authenticity could be doubted. Yet, Peterson (2010) argues that a recognition of this type of subjective accounts of sexual empowerment still may be valuable in that it validates women's own experiences and voices. Indeed, if the participants' own perspectives of events are accepted, it is possible to suggest that sexual empowerment might best be understood as individually colored, experience-based, developmental processes rather than as something that is brought about primarily through collective, formal sex education.

Within such developmental processes it is also important to recognize that amidst undesirable experiences, there are also many desirable, pleasurable and strengthening ones. Narratives about ambiguous communication, romance gaps, manipulation tactics, bodily exploitation, potential rape, and instrumental sex, blend with narratives about communicative prowess, sexual assertiveness, refusal stamina, sexual independence, erotic gratification, and sexual relaxation. As Fine (1988) pointed out some time ago, modern sex education needs to acknowledge this double nature of sexual experiences instead of one-sidedly accentuating its risky nature. In line with this, we also sympathize with Lamb (2010) who, in defending a "model of mutuality," argues that young women always need to be reminded that "equality and mutuality is an ethical ideal to aim for while sometimes hard to achieve" (p. 303). Indeed, the establishment of a pure relationship, whether temporary or long-term, is probably always a deeply intricate matter.

Finally, a few limitations of this research should be mentioned, all relating to the fact that the participants in the study were a small, homogeneous sample of young women who were selected because of their experiences of casual sex. First, it is still an open question how young females who do not engage in this practice, but who might still be very well-informed, reason about it. Second, the focus on females alone makes it difficult to say whether or not males would agree with the presented picture of events. Third, the findings of the study may not be applicable to other cultural and subcultural settings, particularly those that are very different from Sweden's mainstream secular tradition. All this being said, we still want to emphasize that the voices of the participants often mirrored previous qualitative and quantitative research in the field. 
Acknowledgements Open access funding provided by Linköping University.

\section{Compliance with Ethical Standards}

Conflict of interest Michael Tholander declares that he has no conflict of interest. Ninni Tour declares that she has no conflict of interest.

Ethical Approval All procedures performed in studies involving human participants were in accordance with the ethical standards of the institutional and/or national research committee and with the $1964 \mathrm{Hel}-$ sinki declaration and its later amendments or comparable ethical standards.

Informed Consent Informed consent was obtained from all individual participants included in the study.

Open Access This article is licensed under a Creative Commons Attribution 4.0 International License, which permits use, sharing, adaptation, distribution and reproduction in any medium or format, as long as you give appropriate credit to the original author(s) and the source, provide a link to the Creative Commons licence, and indicate if changes were made. The images or other third party material in this article are included in the article's Creative Commons licence, unless indicated otherwise in a credit line to the material. If material is not included in the article's Creative Commons licence and your intended use is not permitted by statutory regulation or exceeds the permitted use, you will need to obtain permission directly from the copyright holder. To view a copy of this licence, visit http://creativecommons.org/licen ses/by/4.0/.

\section{References}

Ahlmark-Michanek, K. (1962). Jungfrutro och dubbelmoraln[The virginity ideal and the double standard]. Malmö: Cavefors.

Bauman, Z. (2003). Liquid love. Cambridge: Polity.

Beres, M. (2010). Sexual miscommunication: Untangling assumptions about sexual communication between casual sex partners. Culture, Health and Sexuality, 12(1), 1-14.

Boislard, M.-A., van de Bongardt, D., \& Blais, M. (2016). Sexuality (and lack thereof) in adolescence and early adulthood: A review of the literature. Behavioral Sciences, 6(1), 8. https://doi.org/10.3390/ bs6010008.

Brown, J. D. (1955). Sin and Sweden. Time, 65(17), 39.

Bryant, J., \& Schofield, T. (2007). Feminine sexual subjectivities: Bodies, agency, and life history. Sexualities, 10(3), 321-340.

Campbell, A. (2008). The morning after the night before: Affective reactions to one-night stands among mated and unmated women and men. Human Nature, 19(2), 157-173.

Cooper, A., \& Gordon, B. (2015). Young New Zealand women's sexual decision making in casual sex situations: A qualitative study. Canadian Journal of Human Sexuality, 24(1), 69-76.

Dubé, S., Lavoie, F., Blais, M., \& Hébert, M. (2017). Consequences of casual sex relationships and experiences on adolescents' psychological well-being. Journal of Sex Research, 54(8), 1006-1017.

Eisenberg, M., Ackard, D., Resnick, M., \& Neumark-Sztainer, D. (2009). Casual sex and psychological health among young adults. Perspectives on Sexual and Reproductive Health, 41(4), 231-237.

Fahs, B., \& Munger, A. (2015). Friends with benefits? Gendered performances in women's casual sexual relationships. Personal Relationships, 22(2), 188-203.

Farvid, P., \& Braun, V. (2013). Casual sex as "not a natural act" and other regimes of truth about heterosexuality. Feminism and Psychology, 23(3), 359-378.

Farvid, P., \& Braun, V. (2014). The "sassy woman" and the "performing man": Heterosexual casual sex advice and the (re)constitution of gendered subjectivities. Feminist Media Studies, 14(1), 118-134.

Farvid, P., \& Braun, V. (2017). Unpacking the "pleasures" and "pains" of heterosexual casual sex: Beyond singular understandings. Journal of Sex Research, 54(1), 73-90. 
Farvid, P., \& Braun, V. (2018). "You worry 'cause you want to give a reasonable account of yourself": Gender, identity management, and the discursive positioning of "risk" in men's and women's talk about heterosexual casual sex. Archives of Sexual Behavior, 47(2), 1405-1421.

Feldman, S., Turner, R., \& Araujo, K. (1999). Interpersonal context as an influence of sexual timetables of youth. Journal of Research on Adolescence, 9(1), 25-52.

Fine, M. (1988). Sexuality, schooling, and adolescent females: The missing discourse on desire. Harward Education Review, 58(1), 29-53.

Foucault, M. (1978). The history of sexuality (Vol. 1). New York: Pantheon.

Foucault, M. (1986). The history of sexuality (Vol. 3). New York: Pantheon.

Frantzén, L., \& Torekull, B. (1970). Love in Sweden. Stockholm: Svenska institutet.

Fredrickson, B., \& Roberts, T.-A. (1997). Objectification theory. Psychology of Women Quarterly, 21(2), 173-206.

Giddens, A. (1992). The transformation of intimacy. Stanford: Stanford University Press.

Glover, N., \& Marklund, C. (2009). Arabian nights in the midnight sun? Exploring the temporal structure of sexual geographies. Historisk Tidskrift, 129(3), 487-510.

Grello, C., Welsh, D., \& Harper, M. (2006). No strings attached: The nature of casual sex in college students. Journal of Sex Research, 43(3), 255-267.

Hale, F. (2003). Time for sex in Sweden: Enhancing the myth of the "Swedish sin" during the 1950s. Scandinavian Studies, 75(3), 351-374.

Hatfield, E., Luckhurst, C., \& Rapson, R. (2012). A brief history of attempts to measure sexual motives. Interpersona, 6(2), 138-154.

Hird, M., \& Jackson, S. (2001). Where "angels" and "wusses" fear and thread: Sexual coercion in adolescents dating relationships. Journal of Sociology, 37(1), 27-43.

Hollway, W. (1989). Subjectivity and method in psychology. London: Sage.

Jamieson, L. (1999). Intimacy transformed? A critical look at the "pure relationship". Sociology, 33(3), 477-494.

Kaestle, C., \& Evans, L. (2018). Implications of no recent sexual activity, casual sex, or exclusive sex for college women's sexual well-being depend on sexual attitude. Journal of American College Health, $66(1), 32-40$.

Kalish, R., \& Kimmel, M. (2011). Hooking up: Hot hetero sex or the new numb normative? Australian Feminist Studies, 26(67), 137-151.

Karlsen, M., \& Traeen, B. (2013). Identifying "friends with benefits" scripts among young adults in the Norwegian cultural context. Sexuality and Culture, 17(1), 83-99.

Kennair, L., Wyckoff, J., Asao, K., Buss, D., \& Bendixen, M. (2018). Why do women regret casual sex more than men do? Personality and Individual Differences, 127, 61-67.

Kiely, E. (2005). Where is the discourse of desire? Deconstructing the Irish Relationships and Sexuality Education (RSE) resource materials. Irish Educational Studies, 24(2\&3), 253-266.

Lamb, S. (2010). Feminist ideals for a healthy female adolescent sexuality: A critique. Sex Roles, 62(5\&6), 294-306.

Linnér, B. (1965). Society and sex in Sweden. Stockholm: The Swedish Institute.

Linnér, B. (1967). Sex and society in Sweden. New York: Pantheon.

Lovejoy, M. (2015). Hooking up as an individualistic practice: A double-edged sword for college women. Sexuality and Culture, 19(3), 464-492.

Lyons, H., Manning, W., Longmore, M., \& Giordano, P. (2014). Young adult casual sexual behavior: Life-course-specific motivations and consequences. Sociological Perspectives, 57(1), 79-101.

Moran, C., \& Lee, C. (2014). Australian women talk about non-romantic sex. Psychology and Sexuality, 5(3), 210-231.

Morgan, E., \& Zurbriggen, E. (2007). Wanting sex and wanting to wait: Young adults' accounts of sexual messages from first significant dating partners. Feminism and Psychology, 17(4), 515-541.

Nussbaum, M. (1995). Objectification. Philosophy and Public Affairs, 24(4), 249-291.

Owen, J., Rhoades, G., Stanley, S., \& Fincham, F. (2010). "Hooking up" among college students: Demographic and psychosocial correlates. Archives of Sexual Behavior, 39(3), 653-663.

Paul, E., \& Hayes, K. (2002). The causalities of "casual" sex: A qualitative exploration of the phenomenology of college students' hookups. Journal of Social and Personal Relationships, 19(5), 639-661.

Peplau, L., Rubin, Z., \& Hill, C. (1977). Sexual intimacy in dating relationships. Journal of Social Issues, $33(2), 86-109$.

Peterson, Z. (2010). What is sexual empowerment? A multidimensional and process-oriented approach to adolescent girls' sexual empowerment. Sex Roles, 62(5\&6), 307-313. 
Public Health Agency of Sweden. (2017). Sexualitet och hälsa bland unga i Sverige [Sexuality and health among young people in Sweden]. Solna: Folkhälsomyndigheten.

Public Health Agency of Sweden. (2019). Sexuell och reproduktiv hälsa och rättigheter i Sverige 2017 [Sexual and reproductive health and rights in Sweden 2017]. Solna: Folkhälsomyndigheten.

Reay, B. (2014). Promiscuous intimacies: Rethinking the history of American casual sex. Journal of Historical Sociology, 27(1), 1-24.

Rodrigue, C., \& Fernet, M. (2016). A meta synthesis of qualitative studies on casual sexual relationships and experiences. Canadian Journal of Human Sexuality, 25(3), 225-242.

Sigusch, V. (1998). The neosexual revolution. Archives of Sexual Behavior, 27(4), 331-359.

Smith, J., Flowers, P., \& Larkin, M. (2009). Interpretative phenomenological analysis. London: Sage.

Stake, R. (1978). The case study method in social inquiry. Educational Researcher, 7(2), 5-8.

Swedish National Agency for Education. (2014). Sex education. Stockholm: Skolverket.

Swedish National Board of Education. (1957). Handbook on sex instruction in Swedish schools. Stockholm: Skolöverstyrelsen.

Swedish National Board of Education. (1977). Samlevnadsundervisning [Sex education]. Stockholm: Skolöverstyrelsen.

Swedish Research Council. (2011). Good research practice. Stockholm: Vetenskapsrådet.

Timmermans, E., \& Courtois, C. (2018). From swiping to casual sex and/or committed relationships: Exploring the experiences of Tinder users. Information Society, 34(2), 59-70.

Vrangalova, Z., \& Ong, A. (2014). Who benefits from casual sex? The moderating role of sociosexuality. Social Psychological and Personality Science, 5(8), 883-891.

Waller, W. (1937). The rating and dating complex. American Sociological Review, 2(5), 727-734.

Weaver, A., Mac Keigan, K., \& MacDonald, H. (2011). Experiences and perceptions of young adults in friends with benefits relationships. Canadian Journal of Human Sexuality, 20(1), 41-53.

Wentland, J., \& Reissing, E. (2011). Taking casual sex not too casually: Exploring definitions of casual sex relationships. Canadian Journal of Human Sexuality, 20(3), 75-91.

Publisher's Note Springer Nature remains neutral with regard to jurisdictional claims in published maps and institutional affiliations. 